\title{
Caracterização ambiental e socioeconômica da bacia hidrográfica do Rio Branco e Colorado, Rondônia, Brasil
}

O presente estudo teve como objetivo descrever as características ambientais e socioeconômica da Bacia do Rio Branco e Colorado, no intuito de identificar a organização desse território quanto ao uso dos recursos naturais. A caracterização da Bacia foi realizada por meio de levantamento bibliográficos, artigos científicos, base de dados institucionais, contemplando uma breve discussão quali-quantitativa dos aspectos ambientais (geomorfologia, solo e organização territorial) e socioeconômicos (movimentos migratórios, caracterização demografica e atividades econômicas). A Bacia é caracterizada pelos domínios geomorfológicos Depressão do rio Guaporé, Planície Fluvial do rio Guaporé e Planalto e Chapada dos Parecis que são determinadas pelas altitudes do terreno, com solos favoráveis a aptidão agrícola. Estão inseridas na Bacia duas Unidades de Conservação, sendo uma Quilombola, além de duas Terras Indígenas. Essas áreas são importantes habitats para a conservação da vida silvestre e preservação dos recursos hídricos na região. Os municípios com maior área territorial e densidade demográfica inseridos na Bacia são Alta Floresta D'Oeste, São Francisco D'Oeste, Santa Luzia D'Oeste e Alto Alegre dos Parecis. De forma geral os residentes estão localizados na área rural dos municípios, o que proporciona maior uso dos recursos hídricos, utilizando o solo de forma integrada com várias propostas de cadeia produtiva, agrícola e agropecuária, com destaque ao café, soja, milho, pecuária de corte e piscicultura, além da geração de energia elétrica, com a instalação de 8 $\mathrm{PCHs}$, possibilitando o desenvolvimento socioeconômico da Bacia.

Palavras-chave: Amazônia; Gestão Territorial; Espaço Geográfico; Recursos Hídricos.

\section{Environmental and socioeconomic characterization of the Rio Branco and Colorado watershed, Rondônia, Brazil}

\begin{abstract}
The present study aimed to describe the environmental and socio-economic characteristics of the Rio Branco's and Colorado's Basin, to identify the organization of this territory regarding the use of its natural resources. The characterization of the Basin was carried out using bibliographic surveys, scientific articles and institutional database contemplating a brief qualitative and quantitative discussion of the environmental (geomorphology, soil and territorial organization) and socio-economic aspects (migratory movements, demographic characterization and economic activities). The Basin is characterized by the geomorphological domains of the Guaporé River, the Fluvial Plain of the Guaporé River and the Plateau and Chapada dos Parecis, which are determined by their land elevations, with favorable soil for agricultural aptitude. Two Conservation Units are inserted in the Basin (one Quilombola community), in addition to two Indigenous Lands. These areas are important habitats for the conservation of wildlife and the preservation of water resources in the region. The counties with the largest territorial area and demographic density in the Basin are Alta Floresta D'Oeste, São Francisco D'Oeste, Santa Luzia D'Oeste and Alto Alegre dos Parecis. In general, residents are located in the rural area of those counties, which provides greater use of water resources and the use of the soil in an integrated manner with many productive proposals, as agricultural and agricultural chain with emphasis on products like coffee, soybeans, corn, cattle raising, cutting and fish farming. The installation of 8 SHPs provides generation of electric energy and enables the socio-economic development of the Basin.
\end{abstract}

Keywords: Amazon; Territorial Management; Geographic space; Water resources.

Topic: Desenvolvimento, Sustentabilidade e Meio Ambiente

Reviewed anonymously in the process of blind peer.
Received: 01/01/2021

Approved: 28/01/2021
Thalitta Silva Cota (iD

Universidade Federal de Rondônia, Brasil http://lattes.cnpq.br/7933331465289098 http://orcid.org/0000-0003-3983-3715

thalitta.cota@gmail.com

Nubia Deborah Araújo Caramello (it)

Universidade Federal de Rondônia, Brasil http://lattes.cnpq.br/8155132371455051 http://orcid.org/0000-0002-2167-9759 geocaramellofri@gmail.com

Marta Silvana Volpato Sccoti

Universidade Federal de Rondônia, Brasil http://lattes.cnpq.br/8802033326043600 http://orcid.org/0000-0001-5979-3218 martasccoti@unir.br

DOI: 10.6008/CBPC2179-6858.2021.001.0041
Referencing this:

COTA, T. S.; CARAMELLO, N. D. A.; SCCOTI, M. S. V.. Caracterização ambiental e socioeconômica da bacia hidrográfica do Rio Branco e Colorado, Rondônia, Brasil. Revista Ibero Americana de Ciências Ambientais, v.12, n.1, p.506-519, 2021. DOI: http://doi.org/10.6008/CBPC2179-6858.2021.001.0041 


\section{INTRODUÇÃO}

Para alguns pode ser absurdo uma proposta de analise territorial para mediar conflitos hídricos, sobre tudo na Amazônia, onde ainda tem-se por muitos, um olhar romântico, de fator inesgotável dos recursos hídricos na região. No entanto, as formas de uso e ocupação territorial neste ecossistema merecem atenção principalmente, pela crescente presença de conflitos.

Para a definição de planejamento e gerenciamento dos recursos hídricos quanto as pressões são importantes ter uma delimitação de área física, de reconhecimento e caracterização que facilite a gestão, como a adoção das Bacias Hidrográficas como unidade territorial (VILAÇA et al., 2008; LIMA et al., 2016). Partindo assim, de um holístico do espaço vivido, em que aproxima as consequências da grande pressão econômica que leva ao uso e ocupação dos recursos sem vínculo com uma política ambiental, mesmo que essa seja uma das mais modernas do mundo.

Uma das pressões econômicas que visa atender ao crescente mercado consumidor tanto regional quanto internacional é a piscicultura. Sendo o estado de Rondônia promissor no setor econômico aquícola, onde algumas bacias hidrográficas se tornaram destaque nesta produção (CARLSEN et al., 2019) e a bacia hidrográfica do Rio Branco e Colorado também agrega sua contribuição.

A Bacia do Rio Branco e Colorado representa importante papel social e econômico pelos diversos usos dos recursos hídricos, também integra um dos ecossistemas mais rico em biodiversidade, sobretudo nas espécies ictiológicas, pois os rios são considerados berçários naturais da Bacia do Guaporé.

Alguns estudos vêm sendo desenvolvidos na bacia com intuito de identificar suas problemáticas, pontuar os conflitos e de compreender a dinâmica de uso e ocupação. A exemplo, cita-se a Avaliação Ambiental Integrada (AAI) da sub bacia do Rio Branco que foi desenvolvida por Mott Macdonald. Nesse estudo, o autor traz poucas referências acerca da piscicultura na bacia. Já Paula (2018) apresenta o Relatório Técnico do Estudo dos Componente Indígenas (ECI) no Licenciamento Ambiental das Pequenas Centrais Hidrelétricas ( $\mathrm{PCHs}$ ) na bacia do Rio Branco, em que destaca a piscicultura com grande demanda de uso dos recursos hídricos, tanto na produção como no tratamento dos efluentes.

Ainda traça nesse panorama, a Avaliação ambiental da sub bacia do Rio Branco, a qual destaca o diagnóstico qualitativo sobre a água do Rio Branco (CARAMELLO et al., 2016a) e também uma abordagem dos aspectos de gestão participativa, com aplicação de Metodologias de mobilização de atores hidrográficos na Bacia Hidrográfica do Rio Branco e Colorado (CARAMELLO et al., 2016b).

Esses estudos ambientais são realizados numa perspectiva sistêmica e dinâmica, com intuito de planejamento e gestão, sendo importante conhecer as características da bacia para identificação dos conflitos e problemáticas, permitindo compreender os fenômenos sociais e ambientais, pois a gestão em bacia hidrográfica deve abordar tanto as questões ambientais quanto as sociais pelo seu aspecto integrador, levando em consideração a sociedade e suas atividades com o meio em que se encontram, para que a gestão e o planejamento possam ser entendidos de forma integrada (VILAÇA et al., 2009). Assim, a construção de um perfil territorial é importante no processo de identidade e não há a possibilidade de entender o nível de 
organização tomando por base uma única pressão e sem uma reflexão do contexto macro no qual o meio está inserido, sendo necessário, entender a disponibilidade de área, de recurso hídrico para assim compreender os usos.

Diante desse contexto, este estudo teve como objetivo descrever as características ambientais e socioeconômica da Bacia do Rio Branco e Colorado no intuito de identificar a organização quanto ao uso dos recursos naturais e a configuração da identidade da piscicultura nesse território.

\section{MATERIAIS E MÉTODOS}

\section{Área de estudo}

O estudo foi realizado na Unidade de Gestão do Comitê da Bacia Hidrográfica do Rio Branco e Colorado (CBH-RBC) estabelecida pelo Decreto no 19.061 de 31 de julho de 2014 (Figura 1). A Bacia é constituída pelas sub-bacias hidrográficas do Rio Branco $\left(9.337,98 \mathrm{~km}^{2}\right)$ e Rio Colorado $\left(5.436,67 \mathrm{~km}^{2}\right)$ e abrange os municípios de Alta Floresta D’Oeste, Alto Alegre dos Parecis, São Miguel do Guaporé, São Francisco do Guaporé, Parecis, Santa Luzia D’Oeste, Novo Horizonte do Oeste e Nova Brasilândia D’Oeste (RONDÔNIA, 2014).

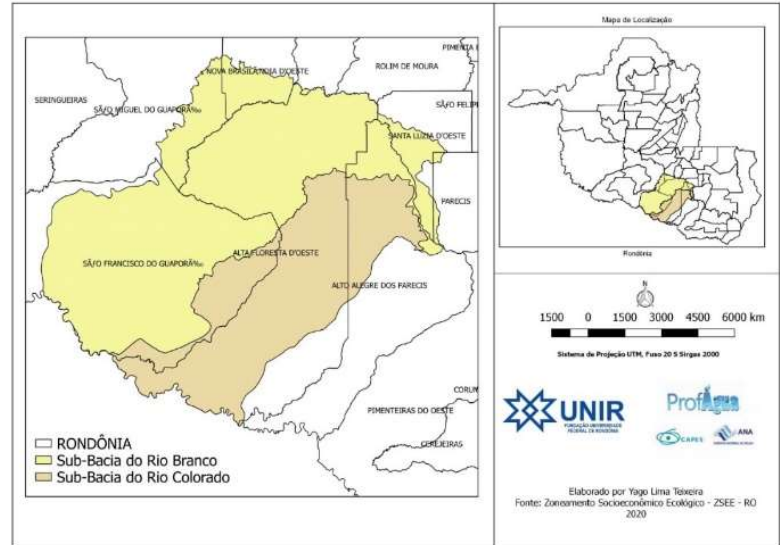

Figura 1: Área de atuação do Comitê da Bacia Rio Branco e Colorado identificando o território das sub Bacia do Rio Branco e do Rio Colorado nos municípios. Fonte: Organizado a partir do banco de dados do ZSEERO.

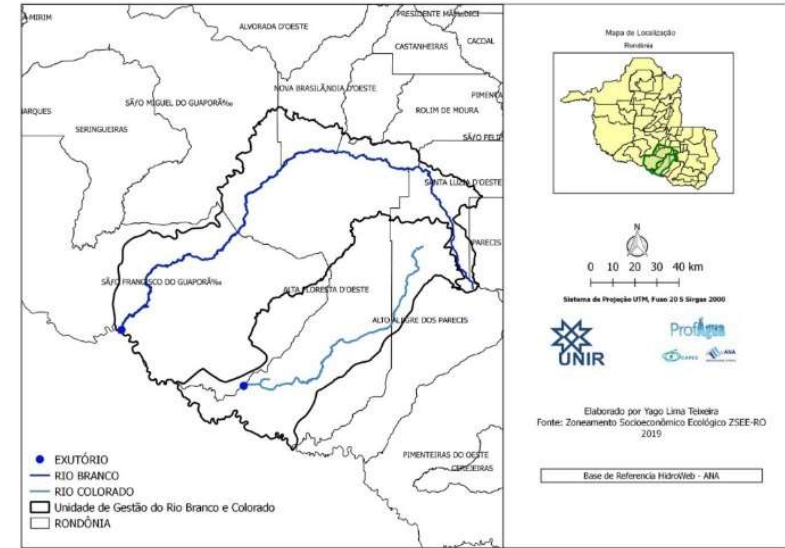

Figura 2: Identificação dos cursos hídricos Rio Branco e Rio Colorado, RO. Fonte: Organizado com base no banco de dados do Domínios hidrológicos ANA.

A Unidade de Gestão da Bacia Rio Branco e Colorado apresenta dois canais principais, os respectivos rios Rio Branco e Colorado que escoam para o Rio Guaporé (Figura 2). A classificação da água dos principais rios da Bacia segundo Goulding et al. (2003) é águas claras, assim como o Rio Guaporé e seus afluentes da margem direita, são águas com alta transparência e visibilidade, quimicamente pobres (oligotróficas) com baixa condutividade e pH ácido-neutro (BARTHEM et al., 2004).

\section{Delineamento da pesquisa}

\section{Coleta de dados}

A caracterização da bacia foi desenvolvida através de pesquisa bibliográfica em dissertações 
(FURLAN, 2016; SILVEIRA, 2017; CAVALHEIRO, 2018), artigos científicos e teses (CARAMELLO et al., 2016a; 2016b; VALE et al., 2012; DANTAS et al., 2010) relatórios técnicos como o Plano Estadual de Recursos Hídricos - PERH-RO (RONDÔNIA, 2018), Avaliação Ambiental Integrada (AAI) da sub bacia do Rio Branco, documentos institucionais como o relatório do Zoneamento Socioeconômico Ecológico de Rondônia (ZSEE-RO) (RONDÔNIA, 2009), informações de Terra Indígena disponibilizada pela Fundação Nacional dos Índios FUNAI, dados referente a Unidade de Conservação, em documentos do Ministério do Meio Ambiente- MMA, consulta ao banco de dados da Secretaria de Estado de Desenvolvimento Ambiental - SEDAM e banco de dados do Instituto Brasileiro de Geográfia e Estatística - IBGE referente aos de dados sociais dos municípios.

\section{Procedimentos de tratamento de informações}

O estudo contemplou uma breve discussão téorica quali-quantitativa das características ambientais e socioeconômicas da Bacia (Figura 3).

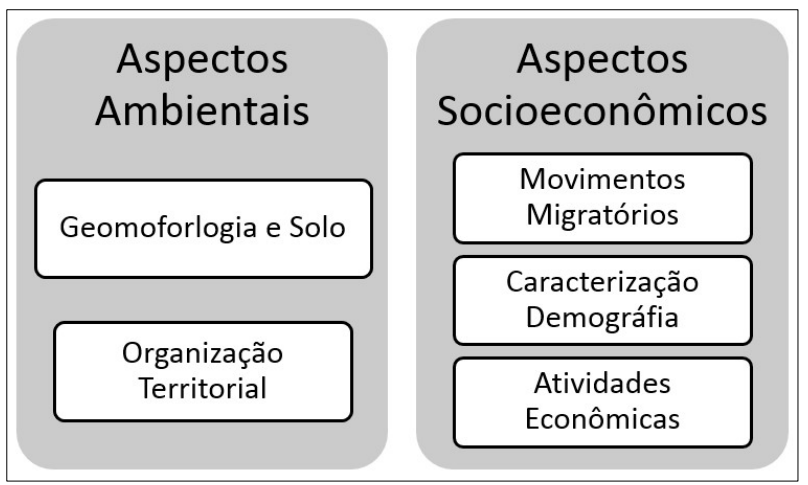

Figura 3: Organização dos dados socioambientais da Bacia do Rio Branco e Colorado em indicadores.

Dos aspectos ambientais abordou-se indicadores que possibilitam a identificação de interação dos recursos da Bacia e a disponibilidade de uso. Para a realização da caracterização socioeconômicos foi adotado o critério de influência territorial e populacional, adaptado ao método utilizado nos estudos de Albuquerque et al. (2011) e Silveira (2017) sendo coletado dados sociais dos municípios que apresentam acima de $30 \%$ da área territorial e maior densidade demográficana área da Bacia em estudo, abordando a relação de uso dos recursos naturais, enfoque aos recursos hídricos a partir da influência territorial possibilitando o desenvolvimento da Bacia a partir das atividades econômicas.

\section{DISCUSSÃO TEÓRICA}

\section{Aspectos ambientais da bacia do Rio Branco e Colorado}

A Bacia do Rio Branco e Colorado abrange três domínios geomorfológicos: Planalto e Chapada dos Parecis, Depressão do rio Guaporé e Planície Fluvial do rio Guaporé que são determinadas pelas altitudes do terreno conforme a compartimentação geomorfológica do estado de Rondônia (DANTAS et al., 2010).

A região compreendida pela área do domínio Planalto e Chapada dos Parecis representa um conjunto de formas de relevo dispostas em superfícies tabulares ou localmente dissecadas em colinas. O domínio é 
delimitado, a sul e a sudoeste, pela Depressão do Rio Guaporé, por meio de rebordos erosivos dissecados, apenas na extremidade ocidental desse planalto. Em Alto Alegre dos Parecis e Alta Floresta do Oeste afloram rochas ígneo-metamórficas de idade mesoproterozoica, compostas por ortognaisses (DANTAS et al., 2009). Neste compartimento geomorfológico estão as nascentes dos rios Branco e Colorado, que até chegar à sua jusante localizada a margem direita do rio Guaporé, passa por inúmeras pressões antrópica devido ao uso do solo.

Nesse domínio observa-se grande taxa de ocupação populacional e com boa parte destinada a intensificação e consolidação das atividades agropecuárias (RONDÔNIA, 2010). Nessa região, ainda observa o solo predominantemente do tipo Neossolo Quartzarênico, considerado como um solo raso e susceptível a erosão, e ausência de vegetação nativa, evidenciando o desenvolvimento de atividades agropecuárias.

O domínio Depressão do rio Guaporé retrata uma área constituída por superfícies aplainadas situadas no interior de uma vasta superfície rebaixada por subsidência tectônica, cujas cotas variam entre 150 e 250 m. Essa depressão apresenta-se, em parte, entulhada por uma sedimentação fluviolacustre recente. Nessa região observa-se presença das Terras Indígenas e Unidades de Conservação com uso restrito dos recursos naturais (RONDÔNIA, 2010).

A Planície Fluvial do rio Guaporé apresenta diques marginais e de inundação adjacentes, abrangendo os rios Rio Branco e Colorado, com cotas ligeiramente mais elevadas, estando recobertas por mata aluvial (DANTAS et al., 2010). As características geomorfológicas de uma bacia hidrográfica podem influenciar no potencial de uso da área e têm relação direta com a qualidade e disponibilidade de água (BRITO et al., 2005) indicando os canais principais e quais locais possuem melhor rede de drenagem (DANTAS et al., 2010).

A estrutura geomorfológica da bacia do rio Branco e Colorado apresenta uma variação de altitude de 80 a mais de 300 metros, do sentido chapada dos Parecis ao domínio Vale do Guaporé, o que proporciona águas com vazão rápidas e rios bem encaixados aproveitados para geração de energia (CARAMELLO et al., 2016), como é o caso da região do alto curso da Bacia do rio Branco e Colorado, marcado pela presença de oito Pequenas Centrais Hidrelétricas-PCHs. O solo predominante na Bacia do rio Branco e Colorado é do tipo Latossolos Vermelhos eutróficos, conferindo áreas de sensibilidade baixa a média a erosão. No entanto, observa-se também solos do tipo Cambissolo, como na porção do alto curso do Rio Branco em certos trechos de Alta Floresta d'Oeste, Nova Brasilândia d'Oeste e Novo Horizonte do Oeste ocorrem solos do tipo Cambissolos Háplicos eutróficos, que são solos jovens e pouco evoluídos, muito susceptíveis à erosão devido à relação textural presente nestes solos, que implica em diferenças na infiltração da água.

Na porção do baixo curso do rio Branco, no trecho do município de São Francisco do Guaporé predominam solos dos tipos Cambissolos Háplicos eutróficos e distróficos e Argilossolos Vermelho Amarelos Distróficos, que são mais susceptíveis a processos erosivos, indicando alta sensibilidade à erosão.

De acordo com Mott Macdonald os aspectos relacionados aos tipos de solos de cada região podem influenciar até a presença ou não de ocupação humana e formas de uso do solo. Nesse contexto, é importante identificar essas características ambientais de uma região, identificando os processos de apropriação e aptidão da área, e conhecer as possíveis ocupações da bacia a partir da formação dos aspectos 
ambientais.

\section{Organização territorial}

A Bacia é marcada pela ocorrência de terras indígenas (TI) e Unidades de conservação (UC), que estão inseridas nos municípios de São Francisco do Guaporé e Alta Floresta D’Oeste e São Miguel do Guaporé, essas áreas apresentam grande diversidade dos recursos naturais, sendo áreas de proteção.

As TI localizadas na bacia são denominadas de TI Rio Branco e TI Massaco (Figura 4).

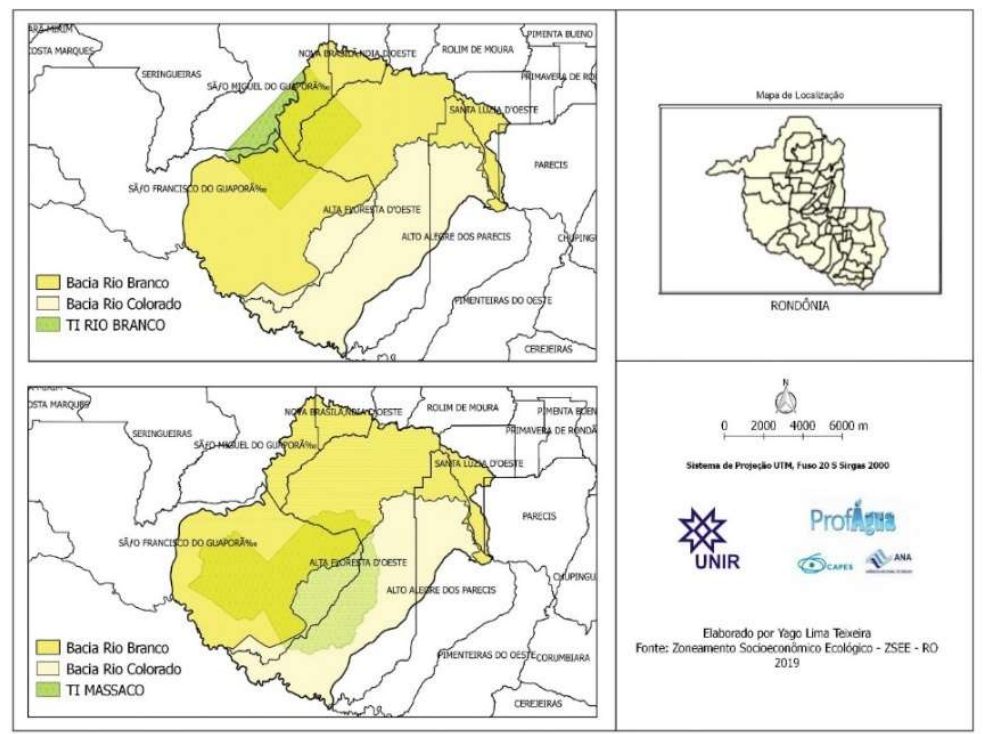

Figura 4: Mapa de identificação das Terras Indígenas na Bacia do Rio Branco e Colorado. Fonte: Idealizado a partir da base de dados ZSEE-RO (RONDÔNIA, 2010).

A TI Rio Branco demarcada com área de 236.137,00 hectares situada parcialmente entre os municípios de São Francisco do Guaporé e São Miguel do Guaporé foi reconhecida e homologada através do Decreto 93.074 de 07 de agosto de 1986. Nela habitam os povos Aikanã, Arikapú, Árua, Djeoromitxí, Kanoê, Makurap e Tupari, esses são indígenas contatados com a sociedade que desempenham atividades econômicas como o comércio de castanha e plantações agrícolas.

O Rio Branco, um dos rios que compõe a Bacia hidrográfica Rio Branco Colorado tem um terço de sua extensão (aproximadamente,133km) no interior dessa TI, o que faz desse rio, um elemento de sobrevivência para os indígenas que o utilizam para agricultura e a pesca de subsistência (PAULA, 2018).

A TI Massaco, demarcada com área de 421.579,00 hectares reconhecida e homologada através do decreto s/n de 14 de dezembro de 1998, tem incidência nos municípios de Alta Floresta d'oeste 14,76\% e São Francisco do Guaporé $28,92 \%$. Possui uma diversidade de cobertura vegetal caracterizada pela Floresta Ombrófila Aberta- 48,13\%, Formações Pioneiras- 25,83\% e Savana- 26,04\%. É habitada por indígenas isolados, sem contato com a sociedade, sendo monitorados pela FUNAI.

As Terras Indígenas representam uma porção do território nacional, de propriedade da União, habitada por um ou mais povos indígenas, os quais utilizam para suas atividades produtivas. São terras imprescindíveis à preservação dos recursos ambientais necessários a seu bem-estar e necessária à sua reprodução física e cultural, segundo seus usos, costumes e tradições. 
A Constituição Federal de 1988, no Art. 231 trata que as Terras Indígenas regularizadas pelo Poder Público devem ser habitadas de forma permanente e são importantes para as atividades produtivas do povo indígena, imprescindíveis à preservação dos recursos necessários ao seu bem-estar e necessárias à sua reprodução física e cultural (BRASIL, 1997). Atualmente, as Terras Indígenas são administrativamente demarcadas pela FUNAI e segue os procedimentos dispostos no Decreto 1.775/1996.

As Unidades de Conservação que estão inseridas na Bacia são a reserva biológica (REBIO) Guaporé e a reserva extrativista (RESEX) Pedras Negras (Figura 5).

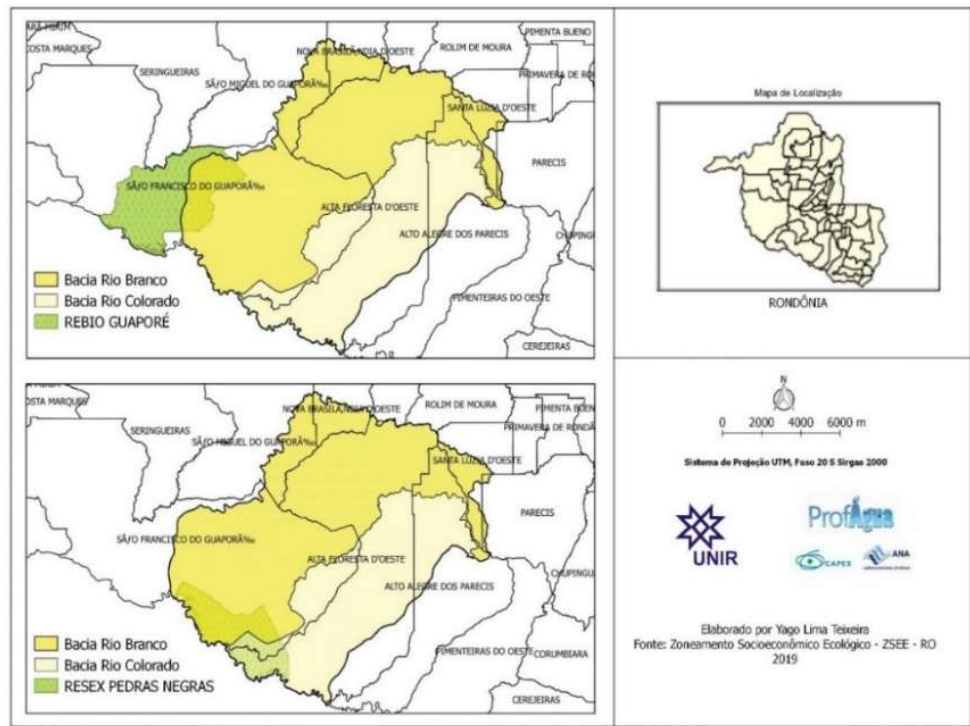

Figura 5: Mapa de identificação das Unidades de Conservação na Bacia do Rio Branco e Colorado. Fonte: Organizado com dados do ZSEE-RO (RONDÔNIA, 2010).

A REBIO do Guaporé possui uma área de 615.771,56 hectares criada pelo Decreto - 87.587 20/09/1982 pertence à categoria de proteção integral sob responsabilidade Federal do ICMBio. A unidade está inserida nos municípios de São Francisco do Guaporé (521.262,33 hectares) que representa 84,44\% de sua área e Alta Floresta D’Oeste (96.038,02 hectares) sendo 15,56\% da área.

A REBIO do Guaporé apresenta vegetação nativa de transição entre o Cerrado e a Floresta Amazônica, bem como as amostras dos ecossistemas aquáticos de rios, lagos, campos e florestas inundáveis. Sua fauna é classificada como uma das mais vastas das províncias zoogeográficas da sub-região Brasiliana, classificando-a como Província Amazônica. De acordo com o Instituto Chico Mendes de Conservação Da Biodiversidade - ICMBio, essa Reserva tem como objetivo preservar espécies raras, ameaçadas ou em perigo de extinção, como o Cervo-do-pantanal (Blastocerus dichotomus), a Onça-pintada (Panthera onca) e a Ariranha (Pteronura brasiliensis), além da preservação das demais espécies de fauna e flora existentes na Reserva.

A Reserva Extrativista Pedras Negras-RESEX, com área de 124.409,00 hectares, situada no município de São Francisco do Guaporé (95.090,81 hectares) em Alta Floresta D’Oeste (31.631,27 hectares) é reconhecida pelo Decreto $n^{\circ} 6.954$ - 14/07/1995 como unidade de uso sustentável sob responsabilidade do Estado de Rondônia por meio da SEDAM. As Reservas Extrativistas segundo o Sistema Nacional de Unidades de Conservação (SNUC - LEI 9.985/2000), compreende a categoria de uso sustentável, utilizada por 
populações extrativistas, para subsistência através do extrativismo e complementarmente com agricultura.

Assim, a RESEX Pedras Negras possui cerca de $2 \%$ de sua área alterada pela presença humana e os povos que à habitam foram os primeiros quilombolas identificados as margens do Rio Guaporé (CARAMELLO et al., 2012). Estima-se haver 113 colocações, mas apenas 19 famílias habitam a reserva. As famílias permanecem, em sua maioria, na Vila de Pedras Negras, característica definida pelas cheias periódicas na região.

Das atividades econômicas na RESEX, a extração das sementes de castanheira (Bertholletia excelsa) é um dos produtos mais importantes, mas também são relevantes a agricultura e a pesca, visto que apresenta uma grande diversidade de espécies íctias, como Tambaqui (Colossoma macropomum), Piranhas (Serrassalmus spp), Pirarara (Phractocephalus hemiliopterus), Caparari (Pseudoplatystoma tigrinum), Pescada (Plagioscion squamosissimus), Surubim (Pseudoplatystoma fasciatum), Jatuarana (Brycon spp), Dourada (Brachyplatystoma rousseauxii) (RONDÔNIA, 2020) dentre outras espécies que são de grande importância ecológica para a Bacia.

Diante desse contexto territorial, é importante frisar que a disponibilidade dos recursos naturais em uma unidade territorial necessita de gestão, planejamento e gerir esse território utilizando-se da bacia hidrográfica, significa uma evolução no modelo de gestão pública (ARAÚJO et al., 2007) sobretudo quando se trata da gestão de recursos hídricos, em que se faz essencial compreender as ações de potencialidade, restrições de usos e a proteção dos recursos naturais, permitindo que se realize o pleno desenvolvimento das funções sociais e do bem-estar de todos, de forma sustentável (CARAMELLO et al., 2012).

\section{Aspectos socioeconômicos da bacia do Rio Branco e Colorado}

\section{Movimentos migratórios}

Os movimentos migratórios na região norte se deu nas décadas de 70 e 80 , em que o território de Rondônia passou-se a Estado em 1981, atraindo um grande número de imigrantes interestaduais, que vinham em busca de terras férteis. Nessa época, eram contabilizados que $57 \%$ dos residentes de Rondônia eram oriundos de outros estados e regiões (BRASIL, 1997; BARBOSA et al., 2016).

Essas tendências migratórias possibilitaram diversos campos de atividades econômicas, sendo as de caráter rural a mais premissa, considerando a diversidade de recursos naturais disponíveis no Estado. A exemplo da sub-bacia do Rio Branco, que aproximadamente 40 anos atrás recebeu oficialmente os primeiros migrantes vindos de outros estados brasileiros, principalmente das regiões Sul e Sudeste e, com eles, uma cultura pecuarista e de produção de café, traçando a partir dessa colonização as características sociais e econômicas da Bacia, resultando em uma dinâmica de apropriação e organização do território (CARAMELLO et al., 2016a).

Esse processo migratório proporcionou o crescimento social da região, sobre tudo por parte governamental, no programa de integração nacional (BRASIL, 1997), que têm na história diversos tempos e espacialidade, com diferentes tendências das atividades econômicas (VALE et al., 2012). 
Nesse sentido, Caramello et al. (2012) trata a Bacia do Rio Branco e Colorado como um local rico em grupos sociais e consequentemente, em aspectos culturais, pois abraça comunidades da floresta (povos indígenas de diversas etnias, comunidades quilombolas, ribeirinhos e extrativistas) e acolhe os imigrantes de diversas regiões do Brasil. Em presença desta análise do perfil territorial da bacia do Rio Branco e Colorado percebe-se uma identidade de colonização espacial e temporal com característica regionalista.

\section{Caracterização demografia}

A bacia abrange oito municípios que estão inseridos de forma parcial na área de atuação do Comitê de Bacia Hidrográfica do Rio Branco e Colorado - CBH-RBC-RO (Tabela 1) evidenciando a participação conjunta de diversas representatividade de atores socais e usuários nas tomadas de decisões da bacia.

Tabela 1: Distribuição da área ocupada de cada município no território da Bacia Hidrográfica do Rio Branco e Colorado, RO.

\begin{tabular}{|c|c|c|c|c|c|c|c|}
\hline Municípios & $\begin{array}{l}\text { Área total } \\
\mathrm{Km}^{2}\end{array}$ & & $\begin{array}{l}\text { Área na sub } \\
\text { Branco (\%) }\end{array}$ & Bacia do Rio & $\begin{array}{l}\text { Área na sub } \\
\text { Colorado (\%) }\end{array}$ & Bacia do Rio & $\begin{array}{l}\text { Total de área } \\
\text { inserido na } \\
\text { CBH-RBC-RO } \\
\text { (\%) }\end{array}$ \\
\hline $\begin{array}{l}\text { Alta Floresta } \\
\text { D'Oeste }\end{array}$ & & 7067.025 & & 40,8 & & 47,25 & 88,05 \\
\hline $\begin{array}{l}\text { Alto Alegre } \\
\text { dos Parecis }\end{array}$ & & 3958.273 & & 10,32 & & 24,94 & 35,94 \\
\hline $\begin{array}{l}\text { São Miguel } \\
\text { do Guaporé }\end{array}$ & & 7460.219 & & 14 & & 0 & 14 \\
\hline $\begin{array}{l}\text { São Francisco } \\
\text { do Guaporé }\end{array}$ & & 10959.767 & & 41,91 & & 7,97 & 49,88 \\
\hline Parecis & & 2548.683 & & 2,01 & & 0 & 2,01 \\
\hline $\begin{array}{l}\text { Santa Luzia } \\
\text { D'Oeste }\end{array}$ & & 1197.796 & & 37,21 & & 0 & 37,21 \\
\hline $\begin{array}{l}\text { Nova } \\
\text { Brasilândia } \\
\text { D'Oeste }\end{array}$ & & 1703.008 & & 5 & & 0 & 5 \\
\hline $\begin{array}{l}\text { Novo } \\
\text { Horizonte do } \\
\text { Oeste }\end{array}$ & & 843.446 & & 0,5 & & 0 & 0,5 \\
\hline
\end{tabular}

Fonte: Organizado a partir do banco de dados do IBGE Cidades e Caramello et al. (2016).

Considerando o critério de análise dos aspectos sociais, apenas 04 dos municípios contemplam a área do seu território acima de 30\% dentro da área da Bacia do Rio Branco e Colorado, sendo o município de Alta Floresta D'Oeste com maior área representativa, seguido de São Francisco D'Oeste, Santa Luzia D'Oeste e Alto Alegre dos Parecis.

O município de Alta Floresta D’Oeste apresenta importante papel no arranjo participativo da gestão dos recursos hídricos na Bacia e é atualmente a sede do Comitê de Bacia do Rio Branco e Colorado-CBH-RBCRO. A Tabela 2 traz a organização demografia dos municípios, com base no censo de 2010 que residem na área da Bacia Hidrográfica do Rio Branco e Colorado considerando o percentual de área de cada município.

Os dados apresentados na Tabela 2 destacam os municípios, Alta Floresta D’Oeste, São Francisco D’Oeste, Santa Luzia D'Oeste e Alto Alegre dos Parecis com maior representatividade de pessoas na área da Bacia. O município de São Miguel do Guaporé também apresenta um número expressivo de pessoas em relação à área da Bacia, no entanto não se enquadra na representatividade dos 30\% de área territorial, devido 
à área estar delimitada por áreas protegidas.

Tabela 2: Distribuição demográfica dos municípios inseridos na Bacia Hidrográfica do Rio Branco e Rio Colorado.

\begin{tabular}{|c|c|c|c|c|}
\hline Municípios & $\begin{array}{l}\text { População total* } \\
\text { (no de pessoas) }\end{array}$ & $\begin{array}{l}\text { Área urbana } \\
\text { (no de pessoas) }\end{array}$ & $\begin{array}{l}\text { Área rural } \\
\text { (no de pessoas) }\end{array}$ & $\begin{array}{l}\text { Número de pessoas } \\
\text { em relação a área na } \\
\text { CBH-RBC-RO** }\end{array}$ \\
\hline Alta Floresta d'Oeste & 24.392 & 13.992 & 10.430 & 21.477 \\
\hline Alto Alegre dos Parecis & 12.816 & 3.665 & 9.161 & 4.606 \\
\hline São Miguel do Guaporé & 21.828 & 8.471 & 13.353 & 3.055 \\
\hline São Francisco do & 16.035 & 8.227 & 7.792 & 7.800 \\
\hline \multicolumn{5}{|l|}{ Guaporé } \\
\hline Parecis & 4.810 & 1.774 & 3.036 & 96 \\
\hline Santa Luzia d'Oeste & 8.886 & 4.525 & 4.361 & 3.307 \\
\hline $\begin{array}{l}\text { Nova } \quad \text { Brasilândia } \\
\text { d'Oeste }\end{array}$ & 19.874 & 8.370 & 11.475 & 994 \\
\hline $\begin{array}{l}\text { Novo Horizonte do } \\
\text { Oeste }\end{array}$ & 10.240 & 1.732 & 8.505 & 51 \\
\hline Total & 118.881 & 50.756 & 68.113 & 41.386 \\
\hline
\end{tabular}

Fonte: Organizado a partir do banco de dados do IBGE Cidades.

Legenda: *censo 2010; **número estimado em relação a \% da área na Bacia.

De forma geral, na maioria dos municípios, os residentes concentram-se na área rural. É importante destacar que a organização espacial dos municípios indica como estes utilizam os recursos para desenvolver as atividades econômicas e de subsistência, tornando a bacia hidrográfica uma unidade de fácil identificação e caracterização (MELO et al., 2016).

Sendo esse território configurado por maior concentração de residentes rurais, entende-se que os usos dos recursos naturais estão voltados para as atividades econômicas de âmbito rural, em que se deve avaliar quais intervenções são necessárias para envolver os atores sociais quanto as reflexões e tomadas de decisões em nível de bacia.

Para Silveira (2017) as comunidades rurais têm importante papel social no contexto de uma Bacia, com cenários conflitantes de uso dos recursos naturais, sendo a agropecuária a principal atividade econômica, com alta concentração na produção de gado de corte, produção de café irrigado, piscicultura e outras culturas, tornando significativo o uso dos recursos hídricos.

\section{Atividades econômicas}

A região utiliza de forma integrada o solo, com várias propostas de produção agrícola e agropecuária, além da presença da piscicultura (Tabela 3) gerando uma dinâmica de gestão nas propriedades rurais, com aproveitamento dos recursos disponíveis para geração da economia.

Tabela 3: Demonstrativo da produção rural da Bacia do Rio Branco e Colorado ano 2018.

\begin{tabular}{llllllll}
\hline \multicolumn{2}{c}{ Produção Rural - ANO 2018 } & & & \\
Atividades & $\begin{array}{l}\text { Alta Floresta } \\
\text { D'Oeste }\end{array}$ & $\begin{array}{l}\text { Alto Alegre dos } \\
\text { Parecis }\end{array}$ & $\begin{array}{l}\text { São Francisco do } \\
\text { Guaporé }\end{array}$ & $\begin{array}{l}\text { Santa } \\
\text { D'Oeste }\end{array}$ & $\begin{array}{l}\text { Luzia } \\
\text { Total produção da } \\
\text { Bacia }\end{array}$ & $\begin{array}{l}\text { Contribuição } \\
\text { Produção de } \\
\text { Rondônia } \\
\text { (\%) }\end{array}$ \\
\hline Pecuária $^{1}$ & 458.185 & 223.515 & 473.412 & 194.936 & $\mathbf{1 . 3 5 0 . 0 4 8}$ & $\mathbf{7 , 0 1 1}$ \\
Agricultura $^{2}$ & 44,293 & 45,471 & 6,317 & 3,680 & $\mathbf{9 9 , 7 6 1}$ & $\mathbf{4 , 0 6 3}$ \\
Piscicultura $^{2}$ & $1.155,213$ & 118,08 & 77,048 & 276,517 & $\mathbf{1 . 6 2 6 , 8 5 8}$ & $\mathbf{3 , 8 2 3}$ \\
\hline
\end{tabular}

Fonte: a partir dos dados IBGE-SIDRA. Legenda: ${ }^{1}$ Efetivo dos rebanhos (Cabeças); ${ }^{2}$ produção em toneladas. Referência de dados: produção de piscicultura foi utilizado das espécies Tambaqui e Pirarucu; para agricultura foi utilizado as culturas de café, mandioca, milho e soja; para pecuária rebanho bovino, suíno e galinha. 
A produção de bovino de corte na região da Bacia tem forte contribuição na pecuária do Estado, pois representa $8,70 \%$ do rebanho bovino efetivo de Rondônia. Mas de encontro com o crescimento dessa atividade tem-se os conflitos ambientais, onde a pecuária de corte, segundo Cavalheiro (2018) está relacionada ao uso de grandes extensões de áreas, o que ocasiona a redução das áreas naturais pois tem ligação direta com o desmatamento para implantação da atividade.

Quanto a produção agrícola, os municípios de Alta Floresta D'Oeste e Alto Alegre dos Parecis apresentam maior quantitativo de produção, com destaque ao cultivo de milho e café que representam respectivamente 1,61\% e 1,03\% da produção agrícola do Estado, esses cultivos também são mencionados por Carvalheiro (2018) que as cita como principais atividades econômicas da Bacia do Rio Branco, além da pecuária de corte.

Na atividade de piscicultura, o município de Alta Floresta do Oeste detém a maior participação em termos de produção, representando $2,71 \%$ da produção de Rondônia, com destaque para a espécie Tambaqui (Colossoma macropomum, Cuvier, 1818). A região de Alta Floresta D'Oeste foi mencionada em estudo de Carlsen et al. (2019) como um dos municípios do Estado com potencial para a piscicultura, sobretudo em áreas de tanques.

Essa contribuição do município de Alta Floresta D’Oeste no contexto da produção rural na Bacia pode estar relacionado a área territorial do município (88,05\%) inserida na Bacia do Rio Branco e Colorado. Essas cadeias produtivas de âmbito rural são componentes importantes para o desenvolvimento econômico setorial de uma região (CASTRO et al., 1998) a exemplo da Bacia do Rio Branco e Colorado é apresentada por Caramello et al. (2012) como região de economia diversificada, que tem na agricultura familiar uma de suas principais vertentes e que apresenta bom desempenho na produção agrícola e na pecuária de corte. A Bacia do Rio Branco e Colorado expõe um território rural que tem sua parcela de contribuição na produção do Estado de Rondônia, e com potencial de crescimento.

Outra forma de uso dos recursos hídricos da Bacia como atividade econômica é a geração de energia elétrica através de Pequenas Centrais Hidrelétricas PCH. Atualmente estão instaladas e operando 8 (oito) PCHs, localizadas na bacia do Rio Branco (Figura 6) essas hidrelétricas são de baixa capacidade instalada (1 $30 \mathrm{MW}$ ) com reservatório ocupando área inferior a $3 \mathrm{~km}^{2}$.

A utilização dos recursos hídricos para implantação das PCHs geralmente está concentrada em tributários de menor porte, visando minimizar o impacto ao meio ambiente, mas a implantação de um conjunto de empreendimentos, ainda que de pequeno porte, em uma mesma bacia hidrográfica pode causar efeitos cumulativos e sinérgicos significativos, principalmente sobre os ecossistemas aquáticos.

Um detalhe importante identificado durante a pesquisa de Mott Macdonald (2018) na Avaliação Ambiental Integrada (AAI) da Bacia do Rio Branco, em relação a instalação da PCH Santa Luzia, localizada no município de Alta Floresta D’Oeste, no rio Colorado, foi o processo de transposição do Rio Branco para Rio Colorado com o objetivo de possibilitar maior disponibilidade de água para acumulo do reservatório da PCH. 


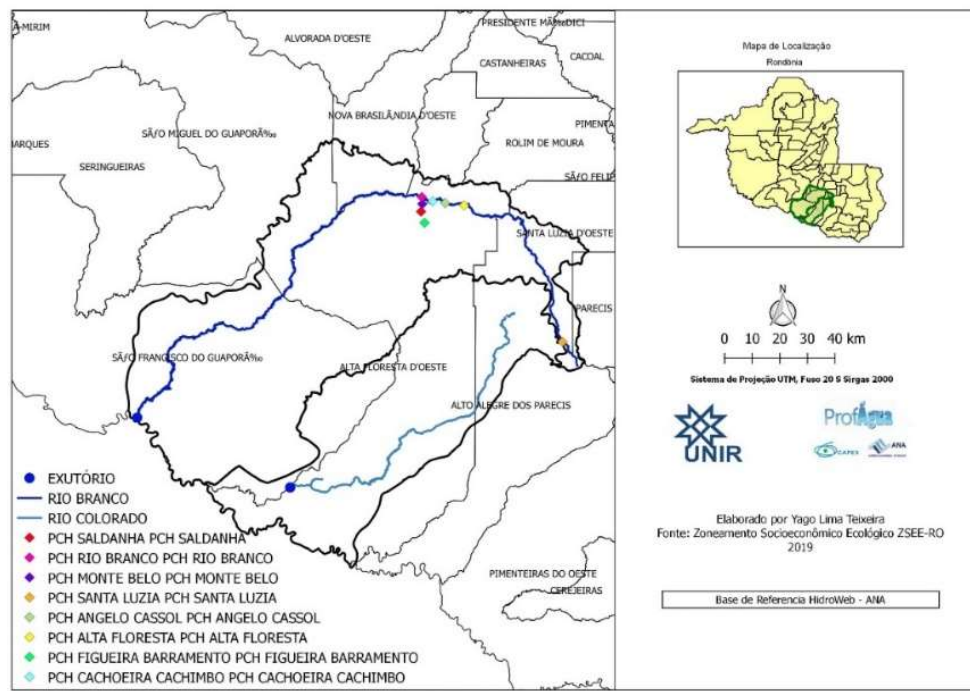

Figura 6: Mapa de identificação das Pequenas Centrais Hidrelétricas na bacia do Rio Branco, RO. Fonte: Idealizado a partir do banco de dados do Domínio hidrológico ANA e SEDAM.

No entanto, esse processo acarreta problemáticas ao meio ambiente, com o comprometimento da movimentação de espécies de peixes migratórios no período de reprodução, quanto ao recurso hídricos, Pagani et al. (2018) destacam que a construção de canais de transposição de passagem de água das PCHs da sub-bacia do rio Branco, pode ocasionar danos ao ciclo hidrológico da bacia principalmente no que diz respeito à redução da vazão dos rios, afetando também os múltiplos usos da água por outros usuários da bacia hidrográfica quanto a operação e gestão desses reservatórios.

De forma geral, é evidente que o uso dos recursos hídricos em uma Bacia está relacionado tanto as atividades sociais, como econômicas, ligados ao conceito de vida da população que reside nessas áreas, de uso rural, urbano e industrial, em que todas essas atividades econômicas refletem na qualidade e disponibilidade dos recursos hídricos da bacia.

No entanto a utilização desse recurso sem gestão da qualidade e quantidade desencadeia inúmeros problemas (MELO et al., 2016) e conflitos, em que as primeiramente afetadas, são as nascentes, as quais, segundo Cavalheiro (2018) são peças importantes nas bacias hidrográficas, pois são responsáveis pelo suprimento de água nos rios, de modo que, a falta de conservação em torno destas áreas pode resultar entre outros, a diminuição da vazão dos rios. A gestão deve ser de forma igualitária, em que todos os usuários possuem direitos e deveres no uso dos recursos hídricos.

Em dados discutidos por Paula (2018) no Estudo Componente Indígena - ECl da Bacia do Rio Branco, pode-se observar que as áreas com cenários de pressão das atividades humanas estão mais frequentes ao norte dos municípios de Alta Floresta d'Oeste e Alto Alegre dos Parecis, já às áreas mais conservadas, estão localizadas no município de São Francisco do Guaporé, relacionados com o predomínio de áreas protegidas conforme apresentado nas Figuras 4 e 5.

Assim, percebe-se que a Bacia do Rio Branco e Colorado apresenta um território de multiplos usos e com distintos atores sociais, onde o gerenciamneto dos recusos hídricos é direcionado pelo Comitê de Bacia Hidrográfica do Rio Branco e Colorado-CBH-RBC-RO, envolvendo todos os setores representativos, sociedade civil, usuários, poderes públicos, que devem dialogar, possibilitando acesso a voz de seus atores sociais. 


\section{CONCLUSÕES}

A área em estudo é formada por uma diversidade cultural de extremo valor para a região Amazônica, esses aspectos também tem intervenção na organização do território e sua estrutura produtiva, sendo identificado na região do alto curso da Bacia uma pressão de uso e ocupação do solo. Sendo que a porção do baixo curso esta inserida unidade de conservação e terras indígenas tem o uso de extrativismo com maior peso, ainda que as comunidades indígenas venham apresentando novas estruturas de uso do solo, inclusive com intencionalidade de implantação da piscicultura em suas terras.

A presente caracterização trouxe a possibilidade de compreensão da identidade da bacia, seus aspectos ambientais, socioeconômico e como essas iniciam um processo de transformação no território através da inserção da piscicultura, de forma que mostra que a Bacia tem uma marca na economia de ambito rural com diversas atividades e que a piscicultura mesmo com pequena contribuição tem potencial para ser desenvolvida. De modo, que se converte pertinente conhecer os atores representativos da piscicultura e suas percepções dos benefícios da atividade na Unidade de Gestão Hidrográfica do Rio Branco e Colorado.

AGRADECIMENTOS: O presente trabalho foi realizado com apoio da Coordenação de Aperfeiçoamento de Pessoal Nível Superior - Brasil (CAPES) - Código de Financiamento 001, agradeço também ao Programa de Mestrado Profissional em Rede Nacional em Gestão e Regulação de Recursos Hídricos - ProfÁgua, Projeto CAPES/ANA AUXPE №. 2717/2015, pelo apoio técnico científico aportado até o momento.

\section{REFERÊNCIAS}

ALBUQUERQUE, M. G.; CAMPOS, M. N.; MOREAU, M. S.. Caracterização ambiental e socioeconômica da Bacia Hidrográfica do Rio Santana. Revista Brasileira de Geografia Física, Recife, p.805-819, 2011.

ARAÚJO, M. M.; ROCHA, R. M. P.; SILVA, B. G.. Gestão Ambiental Participativa: O Planejamento Urbano-Ambiental Sustentável a partir das Bacias Hidrográficas. Revista Fórum de Direito Urbano e Ambiental, v.32, p.34-43, 2007.

BARTHEM, R. B.; FABRÉ, N. N.. Biologia e diversidade dos recursos pesqueiros na Amazônia. In: RUFFINO, M. L.. A pesca e os recursos pesqueiros na Amazônia. Manaus: Ibama, 2004. p.17-62.

BARBOSA, D. C.; FERREIRA, M. M.; DURAN, E.. Gestão de recursos hídricos em bacias urbanas: um estudo de caso na cidade de Porto Velho-Rondônia-Amazônia. p. 180-186. In: NUNES, A.; MOREIRA, C. O.; PAIVA, I. R.; CUNHA, L. S.. Territórios de água. Coimbra: CEGOT - Centro de Estudos de Geografia e Ordenamento do Território, 2016. p.555.

BRASIL, M. C.. Os fluxos migratórios na região norte nas décadas de 70 e 80: uma análise exploratória. Caderno Est. Soc., Recife, v.13, n.1, p.61-84. 1997.

BRITO, L. T. L.; SRINIVASAN, V. S.; SILVA, A. S.; GHEYI, H. R.; GAVIÃO, C. O. Influência da geologia na qualidade das águas da bacia hidrográfica do Salitre, BA. In: SIMPÓsIO
BRASILEIRO DE CAPTAÇÃO E MANEJO DE ÁGUA DE CHUVA, 5. Anais. Teresina, 2005. p.11-14.

CARLSEN, H.; FARIAS, A. R.; FONSECA, M. F.; MAGALHÃES, L. A.. Mapeamento de viveiros escavados no estado de Rondônia por meio de imagens orbitais. In: SIMPÓSIO BRASILEIRO DE SENSORIAMENTO REMOTO, 20. Anais. Santos, 2019.

CAVALHEIRO, W. C. S.. Avaliação ambiental como subsidio para o planejamento e gestão da sub-bacia do Rio Branco, Rondônia. Dissertação (Mestrado em Ciências Ambientais) Universidade Federal de Rondônia-UNIR. Rolim de Moura, 2018.

CARAMELLO, N. D. A.; MARÇAL, M. S.; LIMA, L. F. M.. Desafios para uma gestão ambiental dos recursos hídricos do estado de Rondônia. Revista Geo. Nordeste, n.1, p.49-65, 2012.

CARAMELLO, N. D. A.; PUJOL, D. S; STACHIW, R.; MARTINS, N.. Las aguas del Río Branco hablam por él: el diagnostico cualitativo como instrumento de identificación de la historia ambiental contemporánea del Río Branco, Rondônia, Brasil. In: NUNES, A.; MOREIRA, C. O.; PAIVA, I. R.; CUNHA, L. S.. Territórios de água. Coimbra: CEGOT - Centro de Estudos de Geografia e Ordenamento do Território, 2016a. p.79-89.

CARAMELLO, N. D. A.; ARRUDA, C. S. A.; PENHA, M.; SILVEIRA, I. P.; ELIAS-PIERA, F.; CARDOSO, T. F.; OLIVEIRA, F. 
J.; PUJOL, D. S.; STACHIW, R. T. S.; LIMA, L. F. M.; CAVALCANTE, M. M.; SILVA, J. C.. metodologias de mobilização de actores hidrográficos na Bacia Hidrográfica do Rio Branco e Colorado-Rondônia/Brasil: a informação como instrumento de troca de saberes. In: NUNES, A.; MOREIRA, C. O.; PAIVA, I. R.; CUNHA, L. S.. Territórios de água. Coimbra: CEGOT - Centro de Estudos de Geografia e Ordenamento do Território, 2016b. p.349-358.

CASTRO, A. M. G.; LIMA, S. M. V.; GOEDERT, W. J.; FREITAS FILHO, A.; VASCONCELOS, J. R. P.. Cadeias produtivas e sistemas naturais: prospecção tecnológica. Brasília: Embrapa, 1998.

DANTAS, M. E.; ADAMY, A.. Compartimentação Geomorfológica. CPRM-Serviços Geológico do Brasil, 2010.

FURLAN, V. T.. Terra e política: etnografia da luta antibarragem de indígenas e agricultores contra pequenas centrais hidrelétricas da bacia do Rio Branco (RO). Dissertação (Mestrado em Antropologia social) Universidade Federal de São Carlos, São Carlos, 2016.

GOULDING, M.; BARTHEM, R.; FERREIRA, E.. The Smithsonian Atlas of the Amazon. Washington: Smithsonian Books, 2003.

LIMA, G. A.; GENEROSO, C. M.; SANTOS, C. M.; SILVA, L. A.; SOUSA, R. G.. Bacia Hidrográfica como unidade de planejamento e gestão: Estudo de caso Ribeirão Isidoro. In: CONGRESSO BRASILEIRO DE GESTÃO AMBIENTAL, 7. Anais. Campina Grande, 2016.

MELO, I. S.; SILVA, D. B.; SANTOS, A. L. A.; SANTANA, F. S.; SANTANA, B. L. P.. Atividades antrópicas e degradação ambiental na sub-bacia hidrográfica do rio Itamirim-SE. REGNE, v.2, 2016.

PAGANI, C. H. P.; MASCARENHAS, A. R. P.. Impacto de pequenas centrais hidrelétricas em sub-bacias do rio Branco em Rondônia, Amazônia Ocidental, Brasil. Revista Geográfica Venezolana, v.2, n.52, p.382-396, 2018

PAULA, A. S.. A eficiência do Estudo Componente Indígena no licenciamento ambiental de oito PCH's na sub-bacia Rio Branco no estado de Rondônia. Relatório Técnico. Curitiba: Universidade Federal do Paraná, 2018.

RONDÔNIA. ZSEE-RO - Zoneamento SocioeconômicoEcológico do Estado de Rondônia. Vinte e um anos de Zoneamento Socioeconômico e Ecológico do Estado de Rondônia. Porto Velho, 2010.

RONDÔNIA. PERH - Plano Estadual de Recursos Hídricos do Estado de Rondônia/RE 01. Porto Velho: DOE, 2018.

RONDÔNIA. Decreto n. 19061 de 31 de julho de 2014. Institui o Comitê de Bacia Hidrográfica dos Rios Branco e Colorado - CBH-RBC-RO. Porto Velho: DOE, 2014

RONDÔNIA. Portaria n. 146 de 29 de maio de 2020. Dispõe sobre a proibição da pesca durante o período de reprodução natural dos peixes no Estado de Rondônia e dá outras providências. Porto Velho: DOE, 2020.

SILVEIRA, I. P.. Panorama das políticas públicas em Rondônia: recursos hídricos e resíduos sólidos estruturação, compartimentação e percepções. Dissertação (Mestrado em Ciências Ambientais) - Universidade Federal de Rondônia UNIR, Rolim de Moura, 2017.

VALE, A. L. F.; LIMA, L. C.; BONFIM, M. G.. Século XX: 70 anos de imigração interna no Brasil. Textos \& Debates, n.7, p.2243, 2004.

VILAÇA, M. F.; GOMES, I.; MACHADO, M. L.; VIEIRA, E. M.; SIMÃO, M. R. L.. Bacia Hidrográfica como unidade de Planejamento e Gestão: O estudo de caso do Ribeirão Conquista no município de Itaguara, MG. In: SIMPÓSIO BRASILEIRO DE GEOGRAFIA FÍSICA APLICADA, 8. Anais. Viçosa: UFV, 2009.

A CBPC - Companhia Brasileira de Produção Científica (CNPJ: 11.221.422/0001-03) detém os direitos materiais desta publicação. Os direitos referem-se à publicação do trabalho em qualquer parte do mundo, incluindo os direitos às renovações, expansões e disseminações da contribuição, bem como outros direitos subsidiários. Todos os trabalhos publicados eletronicamente poderão posteriormente ser publicados em coletâneas impressas sob coordenação da Sustenere Publishing, da Companhia Brasileira de Produção Científica e seus parceiros autorizados. Os (as) autores (as) preservam os direitos autorais, mas não têm permissão para a publicação da contribuição em outro meio, impresso ou digital, em português ou em tradução. 